\title{
Brentano on Appearance and Reality
}

\section{Denis Seron}

(Draft) Forthcoming in U. Kriegel (ed.), Routledge Handbook of Brentano and the Brentano School.

Empiricism is one of the most distinctive features of Brentano's work as a whole (see CHAP. 3). "Experience alone is my teacher", he declared on the opening page of his Psychology from an Empirical Standpoint (Brentano 1874: 1/1973a: xxvii). In very general terms, this suggests that his philosophy gives some priority to appearances over objective reality, to the first-person over the third-person perspective. My suggestion in what follows is that Brentano's aim in the Psychology was basically to consolidate his empiricism through a theory of appearance, and that this theory of appearance is identical with his theory of intentionality. I will here discuss two aspects of this view. First, I will argue that Brentano offers an empirical or phenomenological definition of intentionality. Secondly, my claim will be that his theory of intentionality is basically an epistemological theory.

\section{Empiricism}

Brentano's empiricism has two distinct components. The first is the view that all knowledge, including psychological knowledge, is based on experience; the second is the view that all concepts derive from experience. Brentano's theory of intentionality is an empirical theory insofar as it fulfills both conditions. Let us examine this point in a little more detail.

Regarding the first view, it is important to note that Brentano, already in the Psychology, endorses a very strong version of empiricism. What he opposes is not only the speculative rationalism of Hegel and Schelling. He also challenges the Locke-style view that science provides indirect knowledge of substances through their appearances (Brentano 1874: 28/1973a: 19; Brentano 1979: 5ff.; Brentano 1986: 121-2; see also Haller 1989, Potrč 1997). Maybe, he argues, physical phenomena are really caused by things existing in the outside world. However, this does not entail that there holds between them a relation of similarity in virtue of which phenomenological knowledge provides (indirect) objective knowledge. Even accepting that such a relation exists at the level of "spatial phenomena, shapes, and sizes", the same can certainly not be said of many other phenomena that are also studied in physics, for example "the phenomena of light, sound, heat, spatial location and locomotion" (1874: 28/1973a: 19). Knowing physical phenomena does not involve (indirectly) knowing bodies presumed to cause them. Physical phenomena are not such that there really exist bodies that appear in or through them. Rather, if there exist any such bodies (physical substances) in the external world, they simply don't appear at all: "That which truly exists does not come to 
appearance, and that which appears does not truly exist" (1874: 28/ 1973a: 19). In short: all knowledge has as its objects - all scientific theories actually refer to - phenomena and only phenomena. For this reason, some commentators have suggested that Brentano's position in his Psychology is a form of phenomenalism, namely an epistemological or methodological phenomenalism (Tolman 1987, Pacherie 1993: 13, Simons 1995, Crane 2006, Seron 2014).

The implications of this are straightforward. As is well known, intentionality is used in the Psychology to define psychology (see this volume, CHAP. 4). In opposition to other philosophers and psychologists of the time - especially Wundt, the positivists, and the neoKantians - Brentano thought that the sciences differ from one another not primarily by their methods, but by their objects, and that defining psychology consequently involves defining the mental. Since science in general must refer to phenomena and only phenomena, the question is, What is a mental phenomenon? "Our aim," says Brentano, "is to clarify the meaning of the two terms 'physical phenomenon' and 'mental phenomenon', removing all misunderstanding and confusion concerning them" (1874: 111/1973a: 78). Within the flux of what we experience, some phenomena we are aware of have distinctive features that suffice to qualify them as "mental". According to Brentano, intentional directedness is such a feature: necessarily, every mental phenomenon is representational and vice versa (1874: 124-5/1973a: 88-9).

Let us now turn to the second view: all concepts derive from experience (Brentano 1929: 139). According to Brentano, this can be understood in two different ways (Brentano 1976: 3/1988: 1). In a first sense, an empirical concept is a primitive concept directly abstracted from experience. In a second sense, a concept is said to be empirical insofar as it is defined in terms of primitive concepts thus conceived. For example, the concept of a "four-dimensional topoid" is certainly not taken directly from experience, but it is empirical insofar as it is a combination of, say, the concepts "four", "spatial coordinate", and "shape", which are directly taken from experience.

For the sake of convenience, we may call concepts of the first kind "observational" and concepts of the second kind "theoretical". My contention is that, for Brentano, intentionality falls into the second category. In other words: intentionality is not an observational concept, but a compound of observational concepts, hence a concept that is to be defined through observational concepts. Brentano never used the word "intentionality", nor did he use the word "intentional" in the sense of "intentionally directed toward something". He used instead the term "relation to a content" (1874: 124/1973a: 88). Thus, my aim in the following pages is to show that both "relation" and "content" here are to be taken as observational concepts.

\section{Intentionality empirically defined}

Now with this in mind, Brentano's reasoning in the Psychology is simply as follows. First, psychology is defined as the "science of mental phenomena", with the consequence that 
defining what psychology is requires defining what a mental phenomenon is. Secondly, according to Brentano's intentionality thesis - necessarily all mental phenomena are representational and vice versa -, mental phenomena are to be defined in terms of intentionality. Thirdly and finally, intentionality is not a primitive term and still needs to be defined. As a result, the ultimate goal is to define intentionality, namely to define it using concepts that are directly abstracted from experience.

For Brentano as for most empiricist philosophers of his time, defining is not merely clarifying what a word means and how it should be used, but also, and more importantly, indicating what it actually refers to. The relation of equivalence between the definiendum and the definiens means that the actual objects of the concept to be defined must be those objects which the defining concepts directly refer to. And since intentionality is an empirical concept, these objects must be experiential data. In this sense, the definition required must be a phenomenological definition of intentionality (hereafter PDI). As I will try to show, such a definition is the core of Brentano's theory of intentionality in the 1874 Psychology.

Since psychology is the science of mental phenomena, and mental phenomena are essentially representational, it is to be expected that most of the psychologist's judgments will be expressible by sentences with intentional verbs. Accordingly, the question of what the objects of psychology are is equivalent to the question of what sentences of the form " $R$ represents $A$ " refer to. For example, a psychologist affirms that a subject imagines Peter Pan. The question is, What are the objects of this judgment? What does the sentence refer to? When you accept it as true that the subject imagines Peter Pan, are you committed to the existence of Peter Pan? Or to the existence of the subject? Or to neither (or both)?

In a sense, this is a question of "deep grammar". Another way to express the same idea is to say that intentional sentences may be referentially misleading and need to be rephrased. Defining what an intentional fact is requires rephrasing sentences of the form " $R$ represents $A$ " in such a way as to make apparent the objects actually referred to. Debates about Brentano's theory of intentionality are of course rife (see CHAP. 4). Here is what I believe to be Brentano's rephrasing of " $R$ represents $A$ " and hence his definition of intentionality:

(PDI) For all $x, x$ is a representation of $A$ iff $x$ appears and $x$ (really) exists and $A$ does not (really) exist and $A$ appears in $x .^{2}$

Put more simply: something is an intentional act and hence a mental phenomenon if, and only if, it (really) exists and something else that does not (really) exist appears in it. In other words, " $x$ and $A$ appear" is synonymous with " $x$ and $A$ are phenomena" or " $x$ and $A$ are phenomenally conscious" (in the intransitive sense of the term) or " $x$ and $A$ are subjectively experienced". More precisely: $x$ is a mental phenomenon, $A$ is a physical or mental phenomenon.

The overall idea behind (PDI) is fairly intuitive. It is that appearing does not involve existing. Many things appear in your mind, and among them some exist, some do not. When you 
imagine Peter Pan, what appears to you, what you experience, is both Peter Pan and your imagining Peter Pan. Peter Pan does not need to exist for you to imagine Peter Pan - it is a "mere appearance". But your imagining Peter Pan must exist, otherwise you would not imagine Peter Pan.

All the conditions on the right hand side of the biconditional can easily be found in the 1874 edition of the Psychology (Brentano 1874: 14, 114, 124-132/1973a: 10, 81, 88-94). ${ }^{3}$ The most important point for our purposes is that the definiens is only about phenomena and their phenomenal properties. The primitive terms are "appears", "exists", and "appears in", which are observational concepts in the sense indicated above.

Several things should be noted here.

First, (PDI) is obviously false if inner perception is a form of representation. For in this case, $A$ should be the mental act itself and hence be identical with $x$, with the consequence that $x$ should be said to exist and not exist at the same time. For reasons I cannot go into here, I think that inner perception is not a form of representation in the contemporary sense of the word, that is, a mental act that has a "content". In my view, what corresponds to inner perception in (PDI) is the verb “... appears". 4

Secondly, the condition " $A$ does not exist" clearly serves as a criterion for marking off the intentional content $A$ from other parts of the mental act $x$ which are not represented by $x$. For example, both the represented thunder and the auditory perception of it are parts of the act of feeling scared when hearing thunder. But they differ from each other by the fact that the former, unlike the latter, does not need to exist for the whole act to exist.

Thirdly, the conjunction " $A$ does not exist and $A$ appears in $x$ " corresponds to what Brentano ambiguously - calls "intentional in-existence" (intentionale Inexistenz). That the intentional object "intentionally in-exists" means that it is merely "intentional" in the late-medieval sense of the term, namely a mere appearance in the mind. It is thus noteworthy that Brentano uses the term "intentional existence" interchangeably with "phenomenal existence" (1874: 129/1973a: 92).

Fourthly and finally, the condition " $A$ appears in $x$ " turns out to be central for understanding what intentionality means for Brentano. Intentionality is not a metaphysical relation between mind and world; it is better seen as a pheno-mereological relation in virtue of which some phenomena appear in our mind as having a content, that is, as containing in themselves another phenomenon which does not exist. Both kinds of phenomena are, strictly speaking, appearances in the mind, and thus the relation between them is, as Brentano says, a purely "mental relation" (Brentano 1911: 133ff./1973a: 271ff.). That is why Brentano claims that psychology is also concerned with physical phenomena, as far as they are conceived as contents - as psychological features - of mental phenomena (Brentano 1874: 140/1973a: 100). Nonetheless, mental phenomena - phenomena that include within them other phenomena that do not exist - are the proprietary subject matter of psychology. 
"All phenomena," claims Brentano, "are to be called 'inner' because they all belong to one reality, be it as constituents or as correlates” (Brentano 1982: 129/1995b: 137). In Brentano's view, a phenomenon is something that occurs in one's mind in such a way that one is acquainted with it through perception. Since all objects of perception are phenomena, it follows from this that all perception, even so-called outer perception, is in some sense "inner" (Brentano 1874: 128/1973a: 91; Brentano 1982: 129/1995b: 137). Accordingly, "the objects of the so-called external perception... demonstrably do not exist outside of us. In contrast to that which really and truly exists, they are mere phenomena" (1874: 14/1973a: 10).

\section{A phenomenological approach to the problem of intentionality}

The main benefit of this approach, in my view, is that it offers an intuitive solution to the socalled "problem of intentionality", or at least to some version of it. Roughly, the problem of intentionality arises from the fact that some representations seem to represent both something and nothing. On the one hand, your representation of Peter Pan is about something, namely Peter Pan rather than Robin Wood. On the other hand, Peter Pan does not exist and so there is nothing your representation is about. The problem clearly resides in the relational character of intentional verbs, namely in the fact that they grammatically require an object and, at the same time, are often used to express intentional states that have no object. Crane (2001: 23; cf. Kriegel 2007: 307-8) analyzes the problem using the following three propositions:

(PI1) For all $x$, if $x$ represents $A$, then $x$ stands in a relation to $A$.

(PI2) For all $x$, if $x$ stands in a relation to $A$, then $A$ exists.

(PI3) There exists an $x$ such that $x$ represents $A$ and $A$ does not exist.

The conjunction of (PI1) and (PI2) implies that

(PI4) for all $x$, if $x$ represents $A$, then $A$ exists.

The problem lies in the fact that each of the three propositions (PI1-3) seems true individually, but that the conjunction of (PI4) and (PI3) is necessarily false.

The Brentanian strategy for solving the problem of intentionality becomes apparent if, as prescribed in (PDI), we substitute each occurrence of " $x$ represents $A$ " with the equivalent sentence " $x$ appears and $x$ exists and $A$ does not exist and $A$ appears in $x$ ". We then obtain the following propositions:

(PI1*) For all $x$, if $x$ appears and $x$ exists and $A$ does not exist and $A$ appears in $x$, then $x$ stands in a relation to $A$. 
(PI2) For all $x$, if $x$ stands in a relation to $A$, then $A$ exists.

(PI3*) There exists an $x$ such that $x$ appears and $x$ exists and $A$ appears in $x$ and $A$ does not exist.

There are at least two things worth noting here. First, $\left(\mathrm{PI} 1^{*}\right)$ is a tautology, since "... appears in..." denotes a relation. Secondly, the conjunction of (PI $\left.{ }^{*}\right)$ and (PI2*), at least at first glance, implies a contradiction, namely:

(PI4*) for all $x$, if $x$ appears and $x$ exists and $A$ does not exist and $A$ appears in $x$, then $A$ exists.

Since the problem of intentionality lies in the apparent inconsistency of (PI1-3), one may be tempted to conclude that Brentano's phenomenological approach leaves it unsolved.

However, I think there is a flaw in this line of reasoning. My suggestion is that the phrase "... appears in..." actually introduces something fundamentally new, which requires us to approach the problem in quite a different way.

The key point is that, although "... appears in..." certainly denotes a relation, that relation is not of the usual kind. Suppose you hallucinate a ghost in armor standing in the doorway. The ghost appears to you as do the doorway and the armor. Moreover, it is true that he appears in the doorway and in armor. However, "the ghost is in the doorway" and "the ghost is in armor" do not imply that the ghost or his armor exist. In consequence, (PI2) is false: some relations are such that some or even all of their relata do not exist, and this is the case with "... appears in...". In some sense, both relata are required for the ghost and the doorway to stand in the relation "... appears in...". But this simply means that both relata must appear (not exist) for the relation to appear. (PI2) is certainly true of real relations, but it is not true of purely phenomenal relations: “... appears in..." is not a relation such that, if $x$ stands in a relation to $y$, then $y$ exists.

Most importantly, this is not just a stipulation required in order to accommodate the fact that some representations have no object. Rather, this is just how we use appearance words in ordinary language. In this respect, Brentano's phenomenological approach to the intentionality problem may be considered more intuitive than the approach using intentional verbs (Seron, forthcoming).

Brentano conceives of intentionality as a "relation to a content" (1874: 124/1973a: 88). However, this "mental relation", although similar to real relations, is not a genuine relation and one could even doubt whether it is really fit to be called a relation. ${ }^{5}$ The reason for this, Brentano argues, is that the mental relation can obtain even if one of its relata does not exist: 
thinking. The terminus of the so-called relation does not need to exist in reality at all. (Brentano 1911: 134/1973a: 272)

It is clear that, once intentionality is construed as involving no real relation, that is, no relation such that it cannot obtain unless all its relata exist, the so-called "problem of intentionality" ceases to be a problem at all. Indeed, the conjunction of (PI1) and (PI2) no longer implies (PI4). From the fact that intentionality is a phenomenal relation and all real relations are such that their existence necessarily entails that of all their relata, it does not follow that intentionality is such that its existence necessarily entails that of all its relata. As a result, the conjunction of (PI1) and (PI2) is consistent with (PI3). The phenomenological approach to intentionality makes this solution more intuitive insofar as it makes more intuitive the view that some relations can obtain in the absence of one or more of their relata.

\section{Brentano's theory of intentionality as an epistemological theory}

The condition " $A$ appears (in $x$ ) and does not exist" - intentional in-existence - has to do with what philosophers call "representational opacity". Just as " $S$ has a representation of $A$ " does not entail that there exists something that is represented by $S$ and is identical to $A$, so " $A$ appears" does not entail that there exists something that appears and is identical to $A$. But what is important here is that, once phenomenologically construed, intentional in-existence is no more a puzzling logical feature of intentional verbs, but is normally allowed by the grammar of appearance words.

To some extent, the above suggests an adverbial theory of intentionality (Moran 1996). The claim that intentionality is not a real relation may be taken to mean that "... represents $A$ " is not a relational, but a one-place predicate. To put it otherwise: the belief that you have a representation of $A$ commits you only to the existence of your representation with its psychological properties, and being about $A$ is just one of these properties. However, Brentano's view actually involves something more.

According to (PDI), a mental act consists in a combination of two phenomena, of which one exists and the other does not. A mental act is basically this: a mental phenomenon appears in such a way that something else, its "content" or "primary object", appears in it. As we have just seen, this content is ontologically speaking nothing more than the act's property of being about this or that. As Husserl claims in the Logical Investigations, the intentional content exists in the act in the same way as the red exists in the red stripe (Husserl 1984: 105106/2001: 230; Husserl 1979: 157).

A highly paradoxical consequence of this is that judgments are not made true by the primary object they are about. The psychologist talks about her past mental states. The physicist talks about colors, shapes, temperatures. None of these things really exist, they are mere appearances. Yet some physical or psychological theories are really true. So what makes them 
true if they are about mere appearances? Mere appearances do not exist and thus cannot make anything true!

Assuming that scientific theories refer not to external reality, but only to appearances in the mind, how is it possible for them to be true? The challenge is twofold. As a phenomenalist, Brentano must deny, for example, that the natural scientist's judgment that some owls are brown is made true by physical substances to which it should correspond. As a "science of physical phenomena", physics has no other objects than (physical) appearances in the mind. However, unlike other phenomenalists, Brentano does not consider such judgments to be illusory, or physical knowledge as such to be impossible: it is true - in the sense of what Brentano sometimes calls "phenomenal truth" (Brentano 1985: 169) - that some owls are brown. So what makes them true? Brentano's view is that the judgment's truthmaker is neither its primary object nor any extra-phenomenal substance. All that we have is its secondary object, namely the mental act the natural scientist presently experiences.

Accordingly, there is a sense in which Brentano's theory of intentionality is an epistemological theory, in the sense that its purpose is to establish the validity of the empirical sciences, that is, of sciences whose objects are only mere phenomena. Brentano tries to demonstrate that a science can yield truths even if its objects are mere phenomena. And his solution is as follows: the natural scientist can say true things about physical phenomena, but she ought to know that she actually refers only to present mental phenomena, for example to her remembering of the owl. The upshot of this is that

\footnotetext{
If we investigate what it means to say the color is not known as actually existing, but as phenomenally existing, it becomes clear that in the final analysis I do not know that a color exists, but that I have a presentation of the color, that I see it... Hence it follows that we do not really recognize that which is known as the "object", what we recognize is only the mentally active being who has it as his object... It is certain that neither we nor any other being who grasps something with direct evidence as a fact can have anything but himself as the object of his knowledge. (Brentano 1928: 4-6/1981b: 5-6)
}

This view may be regarded as a variant of the "thesis of the relativity of knowledge" (defended, among others, by Lotze and Hamilton). "The truth of physical phenomena," Brentano claims in the 1874 Psychology, "is only a relative truth" (1874: 28/1973a: 19). The owls that the knowledge that some owls are brown is about are no more than "correlates" that appear in the mental act.

As Brentano put it in the late 1880s, the owls are presented "in an oblique mode" (in modo obliquo) as brown. ${ }^{7}$ The oblique mode corresponds to intentional aboutness, while the real reference, the existing object that is presented in a direct mode (in modo recto), is the present mental act. The empirical scientist's judgments rest upon oblique presentations. The idea is that, although owls are mere appearances, they can be truly ascribed objective properties through a non-referential use of language (cf. Parsons 2004: 179-80). Again, this nonreferential use is in line with our ordinary use of appearance words. We obviously can, in 
virtue of the grammar of appearance words, say true things about appearances that do not exist, for example "The ghost appears to me in armor".

Importantly, this should apply to psychology as well. For the method of empirical psychology is inner observation through memory, and memory is a variety of oblique presentation (Brentano 1928: 38ff.; Dewalque 2014: 68-9). Affirming or knowing that you felt angry a moment ago involves accepting as existent not your past feeling - which indeed no longer exists - but your present memory of having felt angry. Your anger is what your judgment is about, not the object it actually refers to. Psychology, like natural science, pertains to oblique knowledge.

\section{References}

Brentano, F. (1874). Psychologie vom empirischen Standpunkt. Hamburg: Meiner. Engl. transl. (1973a): Psychology from an Empirical Standpoint (A.C. Rancurello, D.B. Terrell, \& L.L. McAlister, Trans.). London and New York: Routledge.

Brentano, F. (1925). Psychologie vom empirischen Standpunkt. Vol. 2: Von der Klassifikation der psychischen Phänomene. Leipzig: Meiner. Engl. transl.: Psychology from an Empirical Standpoint (A.C. Rancurello, D.B. Terrell, \& L.L. McAlister, Trans.). London and New York: Routledge.

Brentano, F. (1928). Psychologie vom empirischen Standpunkt. Vol. 3: Vom sinnlichen und noetischen Bewusstsein. Äussere und innere Wahrnehmung, Begriffe. Lepizig: Meiner. Engl. transl. (1981): Sensory and Noetic Consciousness. Psychology from an Empirical Standpoint III. (M. Schättle \& L.L. McAlister, Trans.). London and New York: Routledge.

Brentano, F. (1929). Über die Zukunft der Philosophie, nebst den Vorträgen Über die Gründe der Entmutigung auf philosophischen Gebiet, Über Schellings System, sowie 25 Habilitationsthesen. Hamburg: Meiner.

Brentano, F. (1976). Philosophische Untersuchungen zu Raum, Zeit und Kontinuum. Hamburg: Meiner. Engl. transl. (1988): Philosophical Investigations on Space, Time and the Continuum (B. Smith, Trans.). London, New York, Sydney: Croom Helm.

Brentano, F. (1979). Untersuchungen zur Sinnespsychologie. Hamburg: Meiner, $2^{\mathrm{d}}$ ed.

Brentano, F. (1982). Deskriptive Psychologie (R. Chisholm \& W. Baumgartner, Eds.). Hamburg: Meiner. Engl. transl. (1995b). Descriptive Psychology (B. Müller, Trans.). London and New York: Routledge. 
Brentano, F. (1985). Kategorienlehre (A. Kastil, Ed.). Hamburg: Meiner.

Brentano, F. (1986). Über Aristoteles: Nachgelassene Aufsätze (R. George, Ed.). Hamburg: Meiner.

Brentano, F. (2010). Logikkolleg EL80 (R. Rollinger, Ed.). Franz Brentano Archiv Graz. URL: http://gams.unigraz.at/archive/objects/context:bag/methods/sdef:Context/get?mode=logik

Crane T. (2001). Elements of Mind. Oxford: Oxford University Press.

Crane, T. (2006). Brentano's concept of intentional inexistence. In: The Austrian Contribution to Analytic Philosophy (M. Textor, Ed.). New York: Routledge, 2006, p. 20-35.

De Libera, A. (2011). Le direct et l'oblique: Sur quelques aspects antiques et médiévaux de la théorie brentanienne des relatifs. In: Philosophical Papers dedicated to Kevin Mulligan (A. Reboul, Ed.). Geneva: University of Geneva. URL: http://www.philosophie.ch/kevin/festschrift

Dewalque, A. (2014). Intentionnalité et représentations in obliquo. Bulletin d'analyse phénoménologique, 10/6, p. 40-84.

Farkas K. (2013). Constructing a World for the Senses. In: Uriah Kriegel (ed.), Phenomenal Intentionality. Oxford University Press, pp. 99-115.

Haller, R. (1989). Franz Brentano, ein Philosoph des Empirismus. Brentano Studien, 1.

Hamilton, W. (1859). Lectures on Metaphysics and Logic, Vol. 1: Metaphysics. Boston: Gould \& Lincoln.

Husserl, E. (1979). Aufsätze und Rezensionen (1890-1910) (B. Rang, Ed.). In: Husserliana: Edmund Husserl Gesammelte Werke, Vol. XXII. Den Haag: Nijhoff.

Husserl, E. (1984). Logische Untersuchungen, Vol. II/1: Untersuchungen zur

Phänomenologie und Theorie der Erkenntnis (U. Panzer, Ed.). In: Husserliana: Edmund Husserl Gesammelte Werke, Vol. XIX/1. Den Haag: Nijhoff. Engl. transl. (2001): Logical Investigations, Vol. 1 (J.N. Findlay, Trans.). New York: Routledge.

Kriegel, U. (2007). Intentional inexistence and phenomenal intentionality. Philosophical Perspectives, 21, p. 307-340.

Moran, D. (1996). The Inaugural Address: Brentano's Thesis. Proceedings of the Aristotelian Society, Supplementary Volumes, 70, p. 1-27.

Moran, D. (2000). Introduction to Phenomenology. London, New York: Routledge.

Pacherie, E. (1993). Naturaliser l'intentionnalité: Essai de philosophie de la psychologie. Paris: PUF. 
Parsons, C. (2004). Brentano on judgment and truth. In: The Cambridge Companion to Brentano (D. Jacquette, Ed.). Cambridge: Cambridge University Press.

Potrč, M. (1997). Haller and Brentano's empiricism. In: Austrian Philosophy Past and Present: Essays in Honor of Rudolf Haller (K. Lehrer \& J.C. Marek, Eds.). Dordrecht: Springer.

Potrč, M. (2013). Phenomenology of intentionality. In: Themes from Brentano (D. Fisette \& G. Fréchette, Eds.). Amsterdam: Rodopi.

Seron, D. (2014). Brentano's “descriptive” realism. Bulletin d'analyse phénoménologique, 10/4, p. 1-14.

Seron, D. (2015). Problèmes de l'auto-représentationalisme. In: Esthétique et complexité II, neurosciences, évolution, épistémologie et philosophie (L.-J. Lestocart, Ed.). Paris: CNRS Editions.

Seron, D. (forthcoming). Intentionalisme et phénoménologie de l'intentionnalité. Études phénoménologiques - Phenomenological Studies.

Simons, P. (1995). Introduction. In: Brentano, Psychology from an Empirical Standpoint (A.C. Rancurello, D.B. Terrell, \& L.L. McAlister, Trans.), with a new introduction by Peter Simons. London and New York: Routledge.

Tolman, C.W. (1987). Intentionality, meaning, and evolution. In: Current Issues in Theoretical Psychology (W.J. Baker, M.E. Hyland, H. Van Rappard, A.W. Staats, Eds.). Amsterdam: Elsevier (North-Holland), p. 365-377.

\footnotetext{
${ }^{1}$ I am indebted to Uriah Kriegel for very insightful comments on an earlier draft of this paper.

${ }^{2}$ The condition " $A$ doesn't exist" on the right hand side of the formula forbids us to quantify over $A$. This impossibility is due to the fact that, as I will argue further on, Brentano plausibly offers an adverbial account of intentionality, construing "... represents $A$ " as a one-place predicate.

${ }^{3}$ For further details, see Seron 2014, 2015. This line of interpretation is very close to that of Potrč 2013.

${ }^{4}$ It is true that Brentano conceives of inner perception as a form of "presentation"

(Vorstellung), namely as a "presentation of a presentation" (1874: 179/1973a: 127). The word, however, should not be understood in the contemporary sense of a full intentional state, but rather in the sense of the appearance of something in the mind. Dermot Moran rightly points out that "Brentano uses the term 'presentation' much as Locke and Hume used the term 'idea"' (Moran 2000: 45). This is clearly reflected in the following quotes: "As we use the verb 'to present', 'to be presented' means the same as 'to appear'" (Brentano 1874: 114/1973a: 81); "We speak of a presentation whenever something appears to us" (Brentano
} 
1911: 34/1973a: 198). The view proposed here does not rule out the possibility for the mental act to be represented, in the contemporary sense of the word. A mental act can have a mental act as its intentional content. In this case, however, Brentano's view is that the act being represented must be numerically different from the act that represents it. The represented act is a past act - an act which no longer exists really and whose only "existence" is its appearing in one's mind. Of course, (PDI) is not self-contradictory when applied to self-representation thus conceived, namely as a representation of a numerically distinct representation.

${ }^{5}$ Katalin Farkas (2013) has proposed to construe intentionality as an "apparent directedness". I think this is exactly what Brentano had in view when he characterized intentionality as a "mental relation". Brentano's use of the term "relation", however, is rather ambiguous. He sometimes regards intentionality as a special kind of relation (Brentano 1928: 42/1981b: 31; Brentano 1985: 167ff.), sometimes as something that is not really a relation at all, but an appearance of a relation (Brentano 1911: 133ff./1973a: 271ff.).

${ }^{6}$ Cf. Hamilton 1859: 96-7: “All human knowledge, consequently ... all human philosophy, is only of the relative or phenomenal. In this proposition, the term relative is opposed to the term absolute; and, therefore, in saying that we know only the relative, I virtually assert that we know nothing absolute, - nothing existing absolutely; that is, in and for itself, and without relation to us and our faculties... It is only in its qualities, only in its effects, in its relative or phenomenal existence, that $<$ the object $>$ is cognizable or conceivable." The terms "correlate" and "phenomenal existence" commonly used by Brentano are clearly Hamiltonian.

${ }^{7}$ Brentano (Ms 13.029[1] at the Graz archives, in Brentano 2010) explains the relation between relativity and obliqueness as follows: "Something that is designated in a relative manner is something that is determined in relation to something else. Relative names are names in which, besides the named object, another object is named in obliquo." See also Brentano 1874: 134ff./1973a: 272ff., Brentano 1985: 169, 174, De Libera 2011. 